\title{
Deactivation of solid catalysts in liquid media: the case of leaching of active sites in
} biomass conversion reactions

\author{
Sádaba, Irantzu; Lopez Granados, Manuel; Riisager, Anders; Taarning, Esben
}

Published in:

Green Chemistry

Link to article, DOI:

$10.1039 / \mathrm{c} 5 \mathrm{gc00804b}$

Publication date:

2015

Document Version

Peer reviewed version

Link back to DTU Orbit

Citation (APA):

Sádaba, I., Lopez Granados, M., Riisager, A., \& Taarning, E. (2015). Deactivation of solid catalysts in liquid media: the case of leaching of active sites in biomass conversion reactions. Green Chemistry, 17(8), 4133-4145. https://doi.org/10.1039/c5gc00804b

\section{General rights}

Copyright and moral rights for the publications made accessible in the public portal are retained by the authors and/or other copyright owners and it is a condition of accessing publications that users recognise and abide by the legal requirements associated with these rights.

- Users may download and print one copy of any publication from the public portal for the purpose of private study or research.

- You may not further distribute the material or use it for any profit-making activity or commercial gain

- You may freely distribute the URL identifying the publication in the public portal 


\title{
Deactivation of solid catalysts in liquid media: Tthe case of leaching of active sites in biomass conversion reactions
}

\author{
Irantzu Sádaba, ${ }^{* a}$ Manuel López Granados, ${ }^{b}$ Anders Riisager ${ }^{c}$ and Esben Taarning ${ }^{a}$
}

Received (in $X X X, X X X)$ Xth $X X X X X X X X X 20 X X$, Accepted Xth $X X X X X X X X X 20 X X$

DOI: 10.1039/b000000x

One of the possible deactivation mechanisms of solid catalysts in liquid phase is the case of leaching, i.e., the loss of active species from the solid that are transferred into the liquid medium. Intriguingly, not many published studies deal with leaching, since this is a specific phenomenon in liquid phase and heterogeneous catalysis occurs traditionally in gaseous phase. However, as a consequence of the 10 development of new processes for biorefieneries, an increasing number of reactions deal with liquid media, and thus, the stability and reusability of solid catalyst in this situation represents a huge challenge that requires specific attention. Leaching of active phases is particularly problematic because of its irreversibility and it can be one of the main causes of catalyst deactivation in liquid media, threatening the sustainability of the process. This tutorial review presents a surveyrevision of the main aspects concerning 15 the deactivation due to leaching of active species from the solid catalyst: mechanisms, detection methods, impact of these factors on the global activity and finally, some procedures to try to minimize the leaching or to cope with it. A decision flowchart is presented to help in the study of the catalyst stability and reusability. Interesting biomass conversion reactions have been chosen as examples to illustrate the importance of these aspects. This review is aimed to be a brief tutorial revision covering the deactivation 20 of solid catalysts in liquid phase, with specific focus on the leaching case, which can be especially helpful to researchers not familiarized with catalytic processes in liquid phase.

\section{Introduction}

As a consequence of the shifting towards renewable feedstock to replace fossil fuels, new catalytic processes are being developed 25 in which the utilization of solid catalysts is preferred. The heterogeneous catalytic processes present the advantage of the easy recovery of the catalyst and the reduction of the waste effluents. Besides, an increasing number of catalytic reactions in biorefining are nowadays being carried out in liquid media. ${ }^{1}$ ${ }_{30}$ Biomass feedstocks have in general low thermal stability, and therefore they are difficult to process in gas phase. ${ }^{2}$ Water is the preferred option for a solvent ${ }_{2}^{3}$ but organic polar solvents ${ }_{;}{ }^{4}$ as well aser even_ionic liquids ${ }^{5-7}$ have been employed in a great number of recent research studieses.-_Some examples of these 35 liquid-phase reactions can be found in the catalytic transformation of the-lignocellulosic biomass to chemicals and fuels, ${ }^{8-10}$ including the hydrolysis of cellulose, ${ }^{11,-12}$ dehydration of carbohydrates $^{13,-14}$ and the subsequent transformation of the platform molecules to value-added chemicals and fuels ${ }^{15,-16}$ or 40 lignin depolymerization. ${ }^{17,-18}$ Also, the transesterification reaction of vegetable oils to produce biodiesel (fatty acid methyl esters, FAME) is carried out in the presence of very polar methanol, $-{ }^{19}$ and the valorization of the sub-product glycerol proceeds in liquid medium. ${ }^{20}$ Finally, the aqueous phase reforming (APR) of 45 biomass-derived-_hydrocarbons in water is another example of liquid-phase reactions in the context of biorefineries. ${ }^{21}$

ThNevertheless, the utilization of a liquid media in a heterogeneously catalyzed reaction can affect the catalyst stability negatively. One of the key factors when so developing an industrial process is the-stability of the catalyst. In this sense, the economic and environmental sustainability of the process depends on the possibility of reusing the catalyst. The usual high price of the components needed for the synthesis of a given catalyst makes the stability of the catalyst an essential 55 requirement for any feasible industrial application. For instance, according to the techno-economic analysis of the industrial production of dimethylfuran (DMF) carried out by Dumesic and co-workers,, the catalyst cost is approximately a third of the total installed equipment cost. ${ }^{22}$ - This is a good example of a prospect 60 reaction within the field of biorefineries using organic solvents. ${ }^{23}$

The catalyst stability and deactivation in gas-solid catalytic reactions have been extensively studied and established in the past years. Numerous reviews, proceedings and investigations address the mechanisms of catalyst deactivation when gas 65 reactants are used and the possibilities of regeneration or prevention of the deactivation. ${ }^{24,-25}=$ However, much less attention 
${ }^{a}$ Haldor Topsфe A/S, Nymollevej 55, 2800 Kgs. Lyngby, Denmark,

E-mail: irsz@topsoe.dk

${ }^{b}$ Institute of Catalysis and Petrochemistry, CSIC, C/Marie Curie 2,

Cantoblanco, 28049 Madrid, Spain

${ }^{c}$ Centre for Catalysis and Sustainable Chemistry, Department of

Chemistry, Technical University of Denmark (DTU) Building 207,

DK-2800 Kgs. Lyngby, Denmark

has- been paid to understand the deactivation processes in liquid

media, probably due to the fact that most of the industrial

catalytic processes are carried out in gas phase. Initial studies

5 covered the stability of supported metal catalysts in liquid phase,

mostly in oxidation reactions. ${ }^{26-28}$ Recently, this problem has

been adressed in the developement of new liquid processes in

biorefineries. ${ }^{2,-29,-30}$ The number of scientific articles related to

catalysis in liquid phase has increased significantly and so, a

0 tutorial reviewision of the main types of deactivation of catalysts

field appears to be of interest. especially for those not

familiarized with the handling of catalyst in liquid phase reaction.

15 a Haldor Topsøe A/S, Nymøllevej 55, 2800 Kgs. Lyngby,

Denmark,Email: irsz@topsoe.dk

${ }^{b}$ Institute of Catalysis and Petrochemistry, CSIC, CAMarie Curie

2, Cantoblance, 28049 Madrid, Spain

E Centre for Catalysis and Sustainable Chemistry, Department of

${ }_{20}$ Chemistry, Technical University of Denmark (DTU) Building

207, DK 2800 Kgs. Lyngby, Denmark

Formatted: English (U.S.)

Field Code Changed

Field Code Changed

Formatted: 08 Article Text 


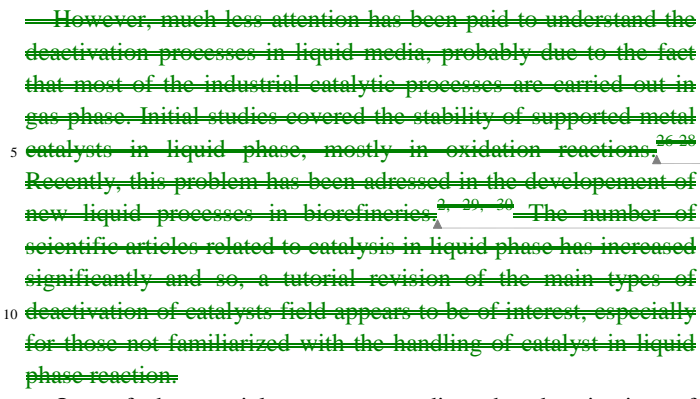

One of the crucial aspects regarding the deactivation of catalyst in liquid media is the possibility of leaching components 15 of the catalyst into the liquid medium. This aspect includes the understanding of the mechanism by which the process takes place, its impact in the deactivation and the catalytic activity, and finally the possibilities of minimizing and/or eliminating this phenomenon. An assessment revision-of these issues will be thus 20 be the main objective of this tutorial review. Although other deactivation mechanisms will be discussed, the main focus of this review will cover the deactivation of catalyst by leaching.

Leaching has economic consequences, especially forin expensive catalysts, and presents very relevant environmental 25 implications. The sustainability of a catalytic process can be threatened by the presence of chemical species in the effluents. Many solid catalysts contain metal species that can be very toxic. Although the extent of leaching represents usually only traces of metal cations-_in the effluent and implicates a low 30 impact in the deactivation, the high toxicity of the leached metal species would require additional purification steps to clean the effluents. This complicates the process and has a negative impact oin its cost.

The present review shows some examples of deactivation of 35 catalysts studied in literature related to biomass conversion reactions. Nonetheless, the aim of the authors -is not to make a thoroughos study of all the published work within this field, but to offer the reader the main guidelines and some representative and illustrative examples.

40 - Finally, although this tutorial review is mainly focused on reactions related to processes in biorefineries, it has a wider scope audience-and is of general interest to other areas dealing with organic reactions conducted in liquid medium and catalyzed by solids, for instance, in the synthesis of pharmaceuticals and other 45 fine chemicals.

\section{Overview of mechanisms of catalyst deactivation}

The process of catalyst deactivation has been widely described in the case of gas-phase reactions. Excellent reviews are reported 50 elsewhere. ${ }^{24,-25}$ Following Bartolomew, there are basically five types of mechanisms of catalyst deactivation in gas-phase that are compiled in Table 1. These five types can be grouped, based on the nature of the mechanism, as physical, thermal and chemical. ${ }^{25}$

${ }^{31}$ Despite this classificationNonetheless, it is not always easy to 55 identify separately the mechanisms causing the catalyst to lose activity. In most of the cases, the deactivation is the result of more than one cause, even having the same effect. The deactivation causes that can take place in liquid medium are similar to those reported in gas phase, although the specific 60 mechanisms differ slightly, as well as their relative relevance.-

The first deactivation causeene, fouling, involves the deposition of chemicals present in the reaction medium on the surface of the catalysts.-_The origin of these species is diverse: 65 reactants, principal products or by-products and even impurities can be physically deposited for a number of reasons, including: heavy weight, insolubility in the reaction medium, steric effects, adsorption, etc. A special fouling case is for Anothere to-reactions in which the products possess larger size than the 70 reactants. The product molecule-of product, once formed, can in this case be occluded in the porous network of the solid. Whichever the reason is, the final result is that reactants do not have an easy access, or no-access at all, to the active sites. There are a number of examples reported in the literature where fouling 75 has occurred. For example, ifn the synthesis of biodiesel with organosulfonic acid functionalized silica as catalysts, catalyst it

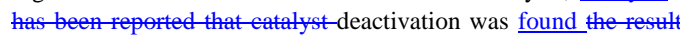
as result of of -site blockage by adsorbed intermediates or byproducts, i.e, fouling. ${ }^{32}$ In gas phase this mechanism is mainly 80 known as coking.-_Coke formation has also been detected in $\mathrm{Ni}$ Co supported catalyst in glycerol reforming to obtain hydrogen. ${ }^{33}$

The second mechanism of deactivation is also physical in $\underline{\text { nature, }}$ and is caused by mechanical alterations of the solid catalyst. The main phenomenon in liquid medium is the attrition, 85 causing the size reduction and/or the breakup of the catalyst particles. ${ }^{24}$ This can be especially problematic when recovering the catalyst. Formation of fine particles too small to be retained or separated can make the reutilization of the catalyst difficult, especially in fluid or slurry beds. When operating in continuous 90 mode the formation of smaller particles can result in clogging and in the subsequent build-up of overpressure in the reactor.

The third type of deactivation is sintering; - _ the thermodynamically driven growth of crystal size. The effects are loss of surface area or even collapse of the porous structure. The 95 diffusion of surface cations or atoms is facilitated by the temperature and as a result, the size of the crystallite of the catalytic component becomes larger. In presence of water, hydrothermal conditions can be specially threatening. The sintering results unavoidably in a loss of the number of active 100 sites exposed to the reaction medium. Sintering of dispersed metals has been described in aqueous medium. ${ }^{34}$ For example, the sintering of Ptplatinum_supported over silica-alumina catalysts occurs faster in liquid water than in wet air, ${ }^{35}$ and the structural stability of different zeolites decrease worsens-significantly in 105 water medium, which needs to be considered carefully in typical biomass conversion processes. ${ }^{36}$ In some cases, the sintering can be avoided by adding promoters that ensure the dispersion of the active metal. ${ }^{33}$ Some of these thermal degradation processes can appear simultaneously. For example, high pressure and 110 temperatures used in glycerol hydrogenolysis caused the collapse of the porous network and sintering of the $\mathrm{Cu}$ metal particles in a silica-supported copper catalyst. ${ }^{37}$

Apart from the mentionedse _ physical and thermal mechanisms, deactivation driven by chemical mechanisms can 115 also take place. PThe poisoning refers to the chemisorption of
Field Code Changed

Field Code Changed 
species that impede the proper functioning of the active site. Traditionally, poisoning has been described as chemisorption of certain substances over metallic particles, but other examples can | refer to ion exchange processes. Sulfonic acid functionalized 5 catalyst or acid sites in general can potentially be deactivated by ion exchange of the protons with metals present in the medium. This behavior has been found in ion exchange resins employed in the esterification of bio-oils, where the main cause of deactivation

| was ion exchange with metal ions. ${ }^{38}=$ Therefore, the presence of 10 impurities in the initial feedstock can potentially deactivate the catalyst. In the esterification and transesterification of oils with sulfonated carbons and silicas as catalysts, the active site is deactivated just after contact with the alcohol. This is explained by the reaction to form sulfonate esters. ${ }^{39,40}$

The fifth deactivation case refers to chemical and structural alterations of the catalyst. It is also chemical in nature, but while the poisoning is an interfacial phenomenon, this mechanism involves the formation of new solid phases. The new phases can

| be formed through the reaction of some of the catalyst ${ }_{20}$ components with any chemical present in the reaction medium

(reactant, product, by-product or impurity) or any other components of the catalyst. Another possibility is a phase change driven by the reaction conditions (temperature, pressure, solvents, etc). Some of the most common deactivation processes gathered in this mechanism include phase transitions by reaction with the solvent, ${ }^{36,-41}$ and dealumination or hydrolysis in the case of zeolites, although this can also be considered as leaching. ${ }^{36}$ Another typical example of formation of new phases is the oxidation of metals by the solvent (water) or oxygen present in 30 the reaction to form catalytic inactive oxides. This has been described in the liquid phase conversion of glycerol with metallic catalysts. ${ }^{42}$ Some authors have even proposed a kinetic model for the mechanism of catalyst deactivation via over-oxidation with oxygen. This is the case in some reactions of oxidation of ${ }_{35}$ alcohols in liquid medium. ${ }^{43,-44}$ Occasionally, a change of phase of the support during the reaction can have a beneficial effect, as in the case of alumina-supported Ptplatinum_catalyst in APR the aqueous phase reforming_of glycerol. Here, the initial alumina forms bohemite, which is active in the reaction of dehydration of ${ }_{40}$ glycerol. ${ }^{45}$ When compared to the deactivation mechanism in gas phase, the chemical alterations in liquid media are more plausible, since the reaction with the solvent is favored to a much greater extent.

Finally, the last deactivation mechanism collected in Table 1 is 45 the lixiviation or leaching of active phases. It is specific for reactions in liquid media and has to do with the solubilization or dissolution of components of the catalyst into the reaction medium. The IUPAC defines it as an extraction procedure, comprising the dissolution of material from a solid phase with a ${ }_{50}$ liquid in which it is not wholly soluble. Strictly speaking, it may be included in the previous category, as it in many cases implies the formation of a new phase that become soluble in the reaction medium. However, in this specific case, the new phase is solubilized into the liquid. It has its counterpart in the gas-phase 55 systems but in this case the phases are volatilized and consequently removed in the gas flow. In batch liquid reactions, the leached species stay in the reaction medium and may play a catalytic role as active species. The problematic_of the stability of solids in water has been-attracteding attention in 60 many studiesfrom many researchers. Sheldon and coworkers studied the case of leaching of variousdifferent_metals in different liquid phase oxidation reactions which they $={ }^{26,46}$ They pointed oupointed out, that stabare ility of solid catalysts is particularly challenging. ${ }^{26,46}$ in this case. In 2002, Okuhara ${ }_{65}$ published a complete review about different water-tolerant solid acid catalysts. ${ }^{47}$ In most of the reported cases, the cause for the deactivation of solid catalysts in liquid media is the partial solubility of the active species in water, i.e.,-_leaching. The support of the catalyst can also be affected during reaction and it 70 can be dissolved in the reaction medium. This happeneds, for example, when using TS-1 zeolite for ammoxidation reactions. The presence of basic ammonia ean-dissolved the silica, and the framework $\mathrm{Ti}$ wasis_transferred and precipitated as $\mathrm{TiO}_{2}$ on the surface of the zeolite ${ }_{-}^{48}=$

${ }^{75}$ _ The growing importance of the leaching phenomenon in catalytic reactions can be perceived by the evolution of scientific documents documents-published in this particular area, as shown by the data in Figure 1. Even though not all the reported search hits are relevant, 80 problematic_of leaching in catalytic conversion of biomass is becoming more visible. Due to its relevance and its peculiar nature and also because of its impact in the environmental sustainability of a given chemical process, it deserves a deeper explanation in this review. Next sections will discuss aspects such 85 as the description of the chemistry behind the leaching of catalytic species, the detection of the leaching phenomena, the determination of the impact in the deactivation, the role of the leached species in the catalytic activity and finally, different manners to prevent or to deal with the leaching. 
Green Chemistry
Cite this: DOI: $10.1039 / \mathrm{c} 0 \times x 00000 x$

www.rsc.org/xxxxxx

\begin{tabular}{|c|c|c|c|c|}
\hline Entry & Nature & Type & Mechanism & Description \\
\hline 1 & Physical & Fouling/coking & Lack of accessibility & $\begin{array}{l}\text { Physical deposition of chemical species by } \\
\text { deposition (fouling). }\end{array}$ \\
\hline 2 & Physical & Mechanical alterations & Loss of active phase or pressure building_up & $\begin{array}{l}\text { Crushing, attrition, abrasion, erosion of the catalyst } \\
\text { particles. }\end{array}$ \\
\hline 3 & Thermal & Sintering & Decrease of the number of exposed active sites & $\begin{array}{l}\text { Loss of surface area or collapse of the porous } \\
\text { network by growth of the crystal size driven by } \\
\text { thermodynamic effects. }\end{array}$ \\
\hline 4 & Chemical & Poisoning & Decline of intrinsic activity & Chemisorption of species on catalytic sites. \\
\hline 5 & Chemical & $\begin{array}{l}\text { Formation of new } \\
\text { inactive phases }\end{array}$ & New phases are not as active & $\begin{array}{l}\text { Reactions of the catalyst leading to different } \\
\text { phases (hydrolysis, hydration, oxidation, etc.) }\end{array}$ \\
\hline 6 & Chemical & Leaching & Loss of active sites & $\begin{array}{l}\text { Dissolution of one or more active components into } \\
\text { the reaction medium. }\end{array}$ \\
\hline
\end{tabular}

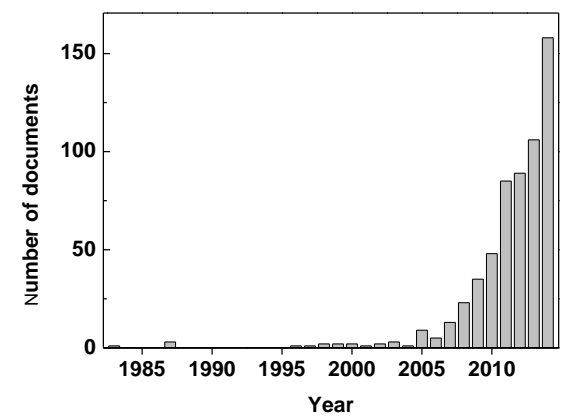

Fig. 1 Evolution of the number of scientific documents published per year using the - Source: Scopus. Hits for-search term: "leaching" (in all fields), 10 and_"catalyst" and "biomass",-_excluding "bioleaching". Source: Scopus

\section{Mechanisms of deactivation by leaching}

It is possibly to One can identify several deactivation mechanisms when deactivation is-caused by leaching, which is

15 And this is relevant when using bulk catalysts, supported catalysts (both support and active phase) as well as -, mixed-phase catalysts.

,etc.

${ }^{20}$ Direct solubilization in the liquid medium. Most of the metal oxides, hydroxides and carbonates frequently present in

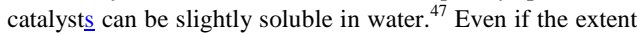

of the leaching is very low, this can have influence on the catalytic behavior and deactivation. When mixed oxides are 25 used, one can have a selective leaching of one of the components. For instance, hydrotalcites in water selectively dissolve $\mathrm{Mg}^{49}$

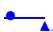

- Chemical transformations. The solvent, or some acids or

${ }_{30}$ bases present in the medium can react with components of the solid catalyst forming soluble species that are subsequently dissolved. In the presence of water, some oxides can form the corresponding hydroxide, with increased solubility. ${ }^{41}$ In the case of oxidation reactions with immobilized metals, leaching is generally due to the solvolysis of the metal-oxygen bonds, through which the active site is attached to the support. ${ }^{26}$ Leaching is particularly increased in the case of oxometal species (e.g. vanadyl, chromyl, molyibdenyl). ${ }^{26}$ When zeolites are used in acidic medium, it is common to have_and-hydrolysis of the $\mathrm{Si}-\mathrm{O}-\mathrm{Al}$ bonds and form extra-framework octahedral $\mathrm{Al}$ species that are easily leached out. ${ }^{36,-50}$ Leaching by chemical transformation is very common when using sulfuric, nitric or hydrochloric acid with metal oxides that can form soluble

45 salts. Basic conditions can also facilitate help in the-leaching. This procedure is habitually used in order to recover metals from spent catalyst. ${ }^{51}$ A modification of this leaching mechanism is when chelating agents are present, like carboxylic acids, polyhydroxy compounds and other organic compounds containing other oxygen, nitrogen or sulfur functionalities. These compounds form complexes with the components of the catalyst, typically metals, and have very effective extractionng_abilities.
Formatted: Space Before: $12 \mathrm{pt}$

Formatted: Font: Not Bold

Formatted: Left, Right: $0 \mathrm{~cm}$, Space Before: 0 pt, Line spacing: Exactly $11,5 \mathrm{pt}$

\section{Formatted Table}

Formatted: Left, Right: $0 \mathrm{~cm}$, Space Before: 0 pt, Line spacing: Exactly $11,5 \mathrm{pt}$

Formatted: Left, Right: $0 \mathrm{~cm}$, Space Before: 0 pt, Line spacing: Exactly

11,5 pt

Formatted: Left, Right: $0 \mathrm{~cm}$, Space Before: 0 pt, Line spacing: Exactly $11,5 \mathrm{pt}$

Formatted: Left, Right: $0 \mathrm{~cm}$, Space Before: 0 pt, Line spacing: Exactly

$11,5 \mathrm{pt}$

Formatted: Left, Right: $0 \mathrm{~cm}$, Space Before: 0 pt, Line spacing: Exactly $11,5 \mathrm{pt}$

\section{Formatted Table}

Formatted: Left, Right: $0 \mathrm{~cm}$, Space Before: 0 pt, Line spacing: Exactly $11,5 \mathrm{pt}$

Formatted: Border: Top: (Single solid line, Auto, 0,5 pt Line width)

Formatted: Font: Italic

Formatted: Justified

Formatted: Font: Italic

Formatted: Indent: Left: $0 \mathrm{~cm}$ Hanging: $0,5 \mathrm{~cm}$, Tab stops: $0,5 \mathrm{~cm}$, Left + Not at $0,35 \mathrm{~cm}$ 


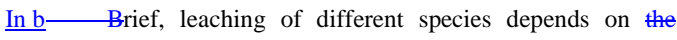
several factors in the reaction medium: $\mathrm{pH}$, oxidation potential, presence of chelating species, temperature and the presence of ions. ${ }^{27}$ Sometimes the reaction conditions can be modified to 5 improve the catalyst stability as it will be explained later, but it is imperative to determine if leaching is taking place, so its impact is minimized.

\section{Detection of the leaching process and activity of leached species}

The detection of the phenomenon of leaching or lixiviation is essential to fully understand the deactivation process. There are several ways of accomplishing this taskmissio as $\mathrm{n}$, which are compiled in Ttable 2 .

$15 \quad$ The first approach consists ofn the chemical analysis of the reaction liquid to identify the presence of soluble species.

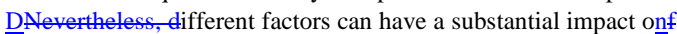
this determination and therefore have to be taken into account. The sampling of the reaction liquid is extremely important. 20 Preferably, the sample has to be taken directly from the reaction medium under relevant reaction conditions. ${ }^{28}$ When this is not feasible, other methodologies can be applied, for instance, hot| filtration or centrifugation. It needs to be commented that the modification of the temperature can affect the solubility of ${ }_{25}$ chemical species, so it is possible that leached species can precipitate at the sampling temperature and leaching phenomena is misinterpreted in the subsequent analysis. Controlling the atmosphere can also be important if the species is expected the species_to be sensitive to the presence of oxygen, moisture, ${ }_{30} \mathrm{CO}_{2}$, etc. and to precipitate before completingmaking - the analysis. The development of procedures for in-situ determination

| of leaching might be is-preferablerequired. In line with thisThus, Granados and coworkers developed an in-situ method to indirectly estimate the amount of leaching in the case of 35 transesterification of triglycerides to produce biodiesel with $\mathrm{CaO}$ by using conductivity measurements. ${ }^{52}$

Table 2 Detection of leaching in the catalyst.

\begin{tabular}{|c|c|c|}
\hline Approach & Measurements & $\underline{\underline{\underline{\text { Remarks }}}}$ \\
\hline Chemical_analysis & Sampling of the reaction & Sampling needs to be \\
\hline \multirow[t]{3}{*}{ of the liquid } & liquid and chemical & representative of the real \\
\hline & $\underline{\underline{\text { analysis- }}}$ & $\underline{\text { reaction situation. }}$ \\
\hline & & to be sensitive enough. \\
\hline
\end{tabular}

Activity of the Contacting the catalyst The leached species do

$\underline{\underline{\text { soluble species }}} \quad \underline{\underline{\text { with the reaction medium. }}}$ and activity measurement be active. of the soluble species-

Characterization Chemical, structural and Information is p플 of the used solid $\quad$ textural analyses about different deactivation $\underline{\underline{\text { mechanisms }}}$, but it can miss the presence of leaching might be $\underline{\text { missed if lixiviation is }}$ limited.

40 Another important factor to take into account is that the detection limit of the analytical techniques employed has to be very low to provide significant results. This is of special importance when determining the leaching extent of supported catalyst, in which the initial loading of the studied element is very

${ }_{45}$ low. Especially when working with low amounts of catalyst, it can happen that leached species cannot be detected, even though they can represent a high percentage of the initial active sites. As an example, in the conversion of cellobiose to sorbitol, $\mathrm{Ru} / \mathrm{C}$ catalyst wasis_used in low amount $(0.0375 \mathrm{~g}$ in $25 \mathrm{~g}$ of solvent), 50 with a low $\mathrm{Ru}$ loading $(3.6 \mathrm{wt} \%){ }^{53}$ The detection limit of the analytical method employed was $2 \mathrm{ppm}$ (ICP-AES), which corresponds to almost $4 \%$ of the initial amount of $\mathrm{Ru}$ present. This means that even if $4 \%$ of the Ru wasis-lost in the reaction it could not be detected. Accordingly, So-it will be difficult to 55 clearly identify the presence of leaching just by analyzing the reaction liquid.

The second approach to detect leaching is based oin the indirect determination of the presence of active soluble species in the reaction medium by testing the catalytic activity of the soluble ${ }_{60}$ species. This can be accomplished made-by separating the catalyst from the reaction medium after a certain time, and continuing the reaction without ence the solid-catalyst has been removed-under the same previous-reaction conditions. Addition of fresh reactants may be useful. An alternative is to contacting 65 the catalyst with only the reaction solvent(s) (without the reactant) under the reaction conditions for a desired time, then separating the solid, and starting the reaction with the liquid phase after addition of the fresh reactant. ${ }^{54}$ This latter approach presents the advantage of a more controlled situation, since other 70 deactivation phenomena, such as deposition of carbonaceous species, are avoided. Carbon deposits can potentially block the access to the active sites and protect them from leaching. However, some of the chemical compounds present in the real reaetion ean also have a big impaet on the leaching. For example, 75 the formation of acid products can decrease the $\mathrm{pH}$ and promote the leaching. Both experiments should thus be done and compared to get extra information and a deeper understanding of the system.

Even very small amounts of solubilized species can represent a 80 large fraction of the overall catalytic activity, leading to a false conclusion on the leaching phenomenon and its impact in the catalyst activity. ${ }^{26,-55}$ Three situations can be found here. I, in the first case, all the activity is due to leached species. This was the case ienf-_the dehydration of xylose to furfural with vanadium 85 phosphate oxides in water-toluene media, where. The authors verified that-several hundreds of $\mathrm{ppm}$ of $\mathrm{V}$ and $\mathrm{P}$ were verified to lead to the same activity results as the total solid catalyst. ${ }^{55}$ If this effect is not identified, wrong conclusions about recyclability and stability of the catalyst can be inferred. In the second case, the 90 leached species can have some extent of contribution to the total activity, or even some kind of synergetic effect. An example
Formatted: Indent: First line: $0,35 \mathrm{~cm}$, Space After: $6 \mathrm{pt}$
Formatted: Space Before: $12 \mathrm{pt}$

Formatted: Font: Not Bold

Formatted Table 
where such synergy effectSome authors identified that the activity was identified is biodiesel production with of a $\mathrm{CsF} / \mathrm{Al}_{2} \mathrm{O}_{3}$ catalyst, in biodiesel resulted from a synergy between alumina and dissolved $\mathrm{CsF}$, the presence of 5 both alumina and dissolved CsF seemed compounds being absolutely necessary to observe any conversion. ${ }^{56}$ Finally, it is important to bear in mind that in other cases, the presence of soluble species has not did not-shown any impact oin the activity. For example, this ox occurreds_ in the oxidation of 510 hydroxymethylfurfural (HMF)_in ionic liquids with when using supported Ru catalysts. Here o@nly the heterogeneous species on the surface of the catalyst presented activity. ${ }^{57}$

The extent of the homogeneous catalysis is not always easy to estimate, as it can vary with the progression of the reaction. This 15 is illustrated -in Thus-several reports on biodiesel production with $\mathrm{CaO}$ catalyst, where authors have evaluated the contribution of the soluble species has been in biodiesel production-with aleim exide catalyst evaluated. Here and found that as reaction progresses, different phases were formed as reaction progressed,

20 changing so changes the leaching phenomena as the solubility of these new species in the reaction medium was different. $^{52,-58}$ In the case of acidic zeolites for fructose dehydration, some authors speculate that primary active species are small zeolite fragments or oligomers containing octahedral or 25 extra-framework aluminum. ${ }^{59}$

Finally _ and additional to the previous experiments_-__a thorough analysis of the used catalyst is important for revealing leaching. It is important to stress that all the measurements directed to detect the leaching should be carried out. If the loss of 30 active species is small and only the spent catalyst is analyzed, it may miss-the detection of leaching may be missed.-- This is why all the approaches are complementary and equally important. Besides, the analysis of the solid is essential for uncovering other causes of deactivation, such as coke formation or sintering.

$35 \div$

$4 \quad$ Formatted: 08 Article Text, Indent: Left: $0 \mathrm{~cm}$

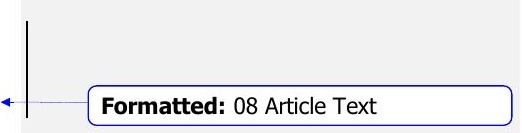




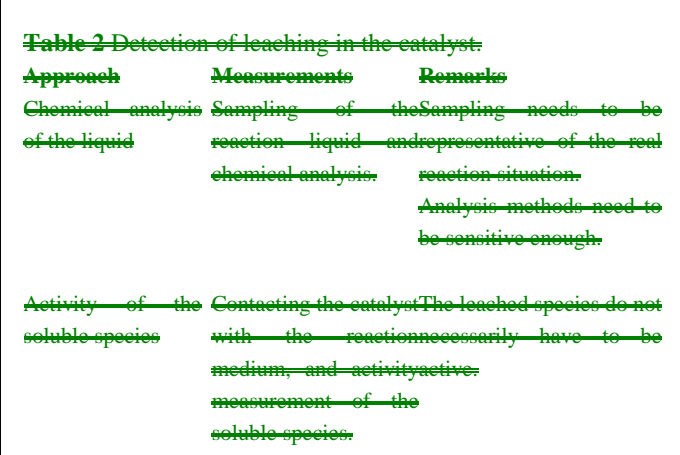

Charaterization of Chemieal, strueturally provides information the ensedid and textural analyses different
deactivation mechanisms
but it ean miss the
presence of leaching if lixiviation is limited.

\section{Leaching and deactivation}

${ }_{5}$ While some of the deactivation processes showed in Table 1 can be reverted, it is very difficult to regenerate a catalyst after leaching. For example, in the case of sugar dehydration to furfural, a deactivation by coke deposition is usually easily solved by calcination of the solid deposits. ${ }^{60}$ However, when the active 10 site of the catalyst is leached, there is a clear loss of active sites and consequently of activity in successive cycles. ${ }^{54}$ This is why the study of the leaching is so important in liquid phase reactions.

Recently, an increasing number of papers have addressed theis problem of catalyst deactivation by leaching of active species to 15 the reaction medium in the field of biorefineries (Figure 1). Most of these studies in litere-are related to the-biodiesel production, probably due to the fact that it is one of the most established biorefinery-related reactions. In a recent review on different-inorganic heterogeneous catalysts for biodiesel 20 production, leaching of active phase was identified as one of the major problems limiting stable performance of the catalyst. ${ }^{61}$ The presence of he-highly polar methanol at relatively high temperatures madekes_the lixiviation process quite favorable. Many of the acidic catalysts studied were based on solids with 25 sulfur-based functionalities. In particular, the lixiviation of sulfonic acid groups in the solid catalysts was identified as the main cause of the deactivation in several differenteases of esterification and transesterification reactions with different catalysts, e.g. $\div$ sulfonated zirconia, ${ }^{62,-63}$ organo sulfonated silica: ${ }^{32}$ 30 and sulfonated carbon ${ }^{6}{ }^{64}$ In other acidic catalysts, like supported heteropolyacids,-_leaching of active phase has been found to occur under reaction conditions. ${ }^{65}$

| Lixiviation leading to catalyst deactivation has also been detected when basic catalysts have been employed in the 35 transesterification reaction. Alkali and alkali-earth oxides, like $\mathrm{CaO}_{-}$_or hydrotalcites, present leaching problems under biodiesel synthesis conditions. ${ }^{52,-66,-67}{ }_{-}$Although some studies report the prevention of the lixiviation by stabilization of the active phase over supports, ${ }^{68}$ other authors have detected leaching in several 40 studies with supported alkalis and metal oxides. ${ }^{69-78}$

Several examples of leaching are also found in other 4 interesting biorefinery-related reactions in liquid phase. This is the case of the hydrogenation of levulinic acid to $\gamma$-gamma valerolactone, where -l leaching of supported metals was ${ }_{45}$ detected using $\mathrm{Ru}-\mathrm{Sn} / \mathrm{C}$ - over carbon- ${ }^{79}$ and $\mathrm{Cu}$-over $\mathrm{ZrO}_{2}{ }^{80}$ This was also the case withef_sufonated amorphous carbon catalyst 4 used in the hydrothermal conversion of cellulose to lactic acid-.4 After the first reaction cycle-of reaction, $40 \%$ of the initial sulfonic groups leached from the catalyst. ${ }^{81}$ In the hydrogenolysis 50 of cellulose to polyols, deactivation by leaching of the supported $\mathrm{Ni}$ and $\mathrm{W}$ over silica-alumina was again observed. ${ }^{82}$ Also, iIn the other-hydrogenolysis reaction_of,-_tetrahydrofurfuryl alcohol to 1,5-pentanediol over $\mathrm{Ir}-\mathrm{Mo} / \mathrm{SiO}_{2}$ catalyst, ${ }_{-}$it was found, that $\underline{\mathrm{Mo}}$ leached into the reaction (Ir remained astable), but Moleached. 55 into the reactions,_causing a loss of activity with time on stream. ${ }^{83}$ Other authors have reported some leaching from metal oxides and functionalized zeolite catalysts in the reacthetion of aldol condensation of furfural and acetone to form larger molecules that can lead to alkanes, using metal oxides and 60 functionalized zeolites as catalysts. ${ }^{41,-84-86}$ In the conversion of lignocellulosic biomass via pyrolysis, metal lixiviation was identified as one of the causes for catalyst deactivation when $\mathrm{Ni}$ nickel_and Cueopper_were supported over ygamma-alumina. ${ }^{87}$ De Vlieger et al. reported the deactivation of $\mathrm{Pt}$ and $\mathrm{Pt}-\mathrm{Ni}$ 65 supported catalyst in APR of ethylene glycol. The proposed mechanism included the leaching and re-deposition of the alumina phase support, causing a loss of exposed area of the metal active sites. ${ }^{88}$

Leaching is obviously an economic problem as it reduces the 70 life of_-__very frequently expensive____catalysts. But the leaching conveys other very important environmental and economic concerns; : the presence of toxic chemical compounds downstream the process. These substances, in some cases heavy metals, must be removed from the streams while they being 75 need to be-handled under appropriate and costly protocols to prevent spills in the environment.

\section{Coping with the leaching}

As seen in the previous examples, there are many cases in which 80 -irreversible catalyst deactivation by leaching is a challenge in a great number of the reactions carried out in liquid phase. Different procedures can be used in order to prevent or minimize the leaching of the catalyst asnd are - summarized in Table 3 . The first approach consists ofn-_the-modification of the reaction 85 conditions. Different factors affect the extent of leaching, as commented in section 3 . First, the solvent significantly affects the behavior of solid catalysts towards leaching. Changing the polarity of the medium is thus one of the easiest options to try to avoid leaching. Diverse examples of this behavior in 90 biorefirenery related reactions have been found in literature.

Changing the solvent from water to methanol avoided the lixiviation of metals in the hydrogenation of levulinic acid. ${ }^{80}$ When recycling mesoporous silica-supported 12tungstophosphoric acid catalysts in the dehydration of xylose to
Formatted: 08 Article Text

Formatted: Justified

Formatted: Justified

Formatted: Justified

Formatted: Justified

Formatted: Justified

Formatted: Justified

Formatted: 08 Article Text, Indent: Left: $0 \mathrm{~cm}$ 
furfural, Valente and coworkers found that the loss of activity in successive runs was significantly lower in DMSO than in water/toluene. ${ }^{54}$ There is also the case of similar materials used in different reactions with very different deactivation profiles. For 5 instance, supported $\mathrm{Ru}$-hydroxide catalysts have been reported to be stable towards leaching in some reactions carried out in non-polar organic solvents, as the oxidation of monoterpenic alcohols in toluene. ${ }^{89}$ In contrast At the same time-, in oxidation of HMF, with a similar supported catyst, lixiviation 10 of Ru species was detected in the liquid after oxidation of HMF with a similar supported catalystren_when ionic liquids were used as solvent. In this latter case, the soluble species were not active in the reaction. ${ }^{90}$ This is a clear example of how important the selection of the reaction medium is when trying to minimize 15 the leaching phenomena.

High pressures can be detrimental for the leaching properties of catalysts.-_When using a zeolite supported vanadia catalyst in the oxidation of HMF no leaching was detected at atmospheric pressure, while But higher extent of leaching was found at 20 higher pressures. ${ }^{91}$ This is a good indication that the parameters of the reaction have a great impact on the stability of the catalyst.

Hydrothermal environments are especially critical for the

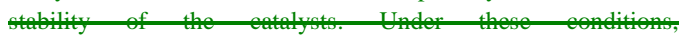
25 mox males haven found to leach when wilized in the conversion of cellobiose to gluconic acid ${ }^{20}$ Other conditions,

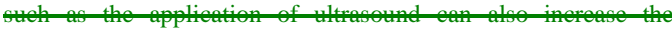
tohing. ${ }^{93}$ The $\mathrm{pH}$ of the medium alo affectubility of

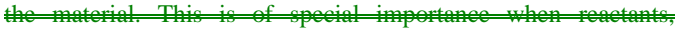
30 products or by products have acidic or basic properties. Vileoeq et al. reported an increas deactivation of a $\mathrm{P} t / \mathrm{Al}_{2} \mathrm{O}_{3}$ eatalyst when formic acid was produced as by product ${ }^{35}$ In a different

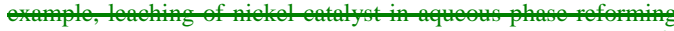
of biomass was prevented by changing to alkaline conditionss ${ }^{94}$ 35 Finally, of the plom in the the extent ferching by reating with the atalyst. This is of the transesterification of oils with high acid content with solid

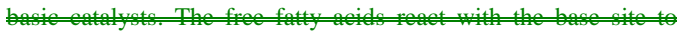
form s, ausing a deactivation by leaching, among other 40 problems.
Table 3 Possible procedures for the prevention of the leaching.

\begin{tabular}{|c|c|c|c|}
\hline Type & Change in & Brief explanation & Refs.eren \\
\hline & & & ees \\
\hline \multirow[t]{4}{*}{$\begin{array}{l}\text { Reaction } \\
\text { conditions }\end{array}$} & Solvent & $\begin{array}{l}\text { Polar solvents are usually more } \\
\text { aggressive }\end{array}$ & $54,-80,-90$ \\
\hline & Pressure & $\begin{array}{l}\text { Higher pressures can affect the } \\
\text { stability }\end{array}$ & 91 \\
\hline & Temperature & $\begin{array}{l}\text { Higher temperatures (hydrothermal } \\
\text { conditions) are usually detrimental }\end{array}$ & 92 \\
\hline & $\mathrm{pH}$ & $\begin{array}{l}\text { High or low } \mathrm{pH} \text { can promote the } \\
\text { solubility }\end{array}$ & $35,-94$ \\
\hline \multirow[t]{4}{*}{ Catalyst } & $\begin{array}{l}\text { Alternative } \\
\text { materials }\end{array}$ & $\begin{array}{l}\text { When possible, use other materials } \\
\text { (metals, supports, etc.) }\end{array}$ & $91,-95$ \\
\hline & Pretreatment & $\begin{array}{l}\text { Different conditions in the } \\
\text { pretreatment modify the } \\
\text { subsequent catalyst }\end{array}$ & $96-98$ \\
\hline & Washing & $\begin{array}{l}\text { Adding a conditioning step in the } \\
\text { synthesis of the catalyst can help to } \\
\text { obtain a stable material }\end{array}$ & o9-101 \\
\hline & $\begin{array}{l}\text { Modifications } \\
\text { of the surface }\end{array}$ & $\begin{array}{l}\text { Metal catalyst can be stabilized } \\
\text { towards leaching by Atomic Layer } \\
\text { Deposition }\end{array}$ & 102 \\
\hline $\begin{array}{l}\text { Reaction } \\
\text { type }\end{array}$ & Gas phase & $\begin{array}{l}\text { Gas phase reactions can-_diminish } \\
\text { problems due to leaching }\end{array}$ & \\
\hline
\end{tabular}

Hydrothermal environments may beare-especially critical for 45 the stability of the catalysts. - Under suchthese conditions, polyoxometalates have been found to leach when utilized in the conversion of cellobiose to gluconic acid. ${ }^{92}$ Other conditions, such as the application of ultrasound, can also increase the leaching. ${ }^{93}$ The $\mathrm{pH}$ of the medium also affects the solubility of 50 the material. This is of special importance when reactants, products or by-products have acidic or basic properties. Vilcocq et al. reported an increased deactivation of a $\mathrm{Pt} / \mathrm{Al}_{2} \mathrm{O}_{3}$ catalyst when formic acid was produced as by-product in ... different example, leaching of Ninickel_catalyst in APR Aqueous 55 hase reforming - of biomass was prevented by changing to alkaline conditions. ${ }^{94}$ Finally, some of the species present in the reaction can aggravate the extent of leaching by reacting with the catalyst. This is ease of the case in transesterification of oils with high acid content usingwith solid basic catalysts. The free fatty 60 acids react with the base-site $=$ to form soaps, causing a deactivation by leaching, among other problems.

-The leaching can secondly be reduced by modifying the catalyst. The type of supported metal also determines the extent of leaching. In the catalytic hydrodeoxygenation (HDO) of 65 vegetable oils to form alkanes, molybdenum carbide exhibited better resistance to leaching than noble metals. ${ }^{95}$ Similarly, And the used support used-can also play an important role on the stability of the-_final catalyst. ${ }^{91}$ Alternative Other-options consists of carrying out some pretreatment procedures on the catalyst.

70 Dumesic and coworkers found that increasing the temperature of the catalyst reduction treatment affected the leaching of Rerhenium _ into the solution in the hydrogenolysis of 2-

\begin{tabular}{|l} 
Formatted: Font: Not Bold \\
Formatted: Centered \\
Formatted: Font: Not Bold \\
Formatted Table \\
Formatted: Font: $8 \mathrm{pt}$ \\
\hline Formatted: Font: $8 \mathrm{pt}$ \\
\hline Formatted: Font: $8 \mathrm{pt}$ \\
\hline Formatted: Font: $8 \mathrm{pt}$ \\
Formatted: Font: $8 \mathrm{pt}$ \\
\hline Formatted: Font: $8 \mathrm{pt}$ \\
\hline Formatted: Font: $8 \mathrm{pt}$ \\
\hline Formatted: Font: $8 \mathrm{pt}$ \\
\hline
\end{tabular}

Comment [arii1]: which reaction?

Formatted: Indent: First line: $0,35 \mathrm{~cm}$ 
(hydroxymethyl) — tetrahydropyran. ${ }^{96}$ The reason for this observation was, is the fact that some possible-rhenium oxide phases are soluble in water, so controlling this aspect is crucial to avoid the solubilization of the catalyst inunder_aqueous reaction 5 environments. The preparation method also plays an important role. While mixed exides-Mg-Al oxides prepared by coprecipitation were found to be unstable in water medium, ${ }^{103}$ a similar synthesis - but involving hydrothermal microwave treatment and an activation step with $\mathrm{Ca}(\mathrm{OH})_{2}$ showed low 10 leaching and better stability. ${ }^{97}-$ - Other modifications of the catalyst can involve the addition of promoters. For example, the addition of $\mathrm{Pt}$ improved the stability of mixed exides $-\mathrm{Mg}-\mathrm{Zr}$ oxide catalysts in furfural valorization with acetone. ${ }^{104}$ The temperatures of the pretreatment and the nature of the organic acid sites can likewise affect the stability, as reported in the dehydration of xylose with arenesulfonic SBA-15 catalysts. ${ }^{98}$ Even a washing procedure or-_treatment can be enough to eliminate_from the surface of the catalyst those-species more prone to leaching from the surface of the catalyst, hence selecting 20 the most stable ones, without affecting significantly the activity. ${ }^{101}$ This happens naturally in successive reaction cycles. It has been frequently observed that the amount of lixiviated material decreases with the cycle number. ${ }^{99,-100,-105}$ - More recently, a very interesting methodology was published by the group of Dumesic's group. ${ }^{102}$ This consisted on stabilization of a Cueoper_catalyst by deposition of a thin layer of alumina by atomic layer deposition (ALD). The overcoat of alumina preventeds the_sintering and leaching of the Cueoper_particles during reaction, generating a . This-catalyst that was stable in the 30 liquid phase hydrogenation of furfural.

Finally, if none of these compiled procedures in Table 3 works, it can be possible to run the reaction in gas phase. Nevertheless, the large_big_polar molecules used in biorefineryrelated reactions are usually nonvolatile and this solution is 35 therefore enot applicableannot be implemented.

\section{Evaluation of the stability and recyclability of a catalyst}

Figure 2 shows athe_decision flowchart that can help to evaluate to in the detand determine ermination of the the stability and recyclability of a solid catalyst in liquid medium. First, experiments directed to the evaluation of the leaching of the catalyst should be carried out. If some extatyst_leaching ing is detected, the next step should be the evaluation of the 45 catalytic activity corresponding to these leached species (see Figure 2). As mentioned earlier, these two actions will confirm the existence of a leaching phenomenaphenomenon.- CBesides, the characterization of the used catalyst can also indicate the presence of the leaching if, for instance, changes in composition to or phases are detected.

- If leaching is detected, it is important to contemplate the necessity of modifying some of the reaction conditions to decrease or minimize the accompanying is-deactivation (Table 3).

The following step is the verification of the catalyst reusability $55_{-}^{-}$, - or in the case of flow reactions _-_, the life time of the catalyst. When dealing with batch reactions, the most common way of testing this is to run consecutive reactions with the catalyst. It is important to note that in some cases when a single measurement is used in the test, the results can be misleading. The deactivation ${ }_{60}$ process can be shadowed depending on the conditions selected in the single measurements. If we consider the deactivation kinetics prevails as of-showned_in Figure 3, it is clear that the activity measurements at different reaction times (1,2 and 3 ) will give an very-altered picture of the deactivation process.--While position 2 65 will clearly prove the presence of deactivation, running the experiment for longer times until position 3 ( 3 h)_will indicate prove the opposite, namely that the catalyst is stable.

-When batch reans are carried out, it must be stressed that

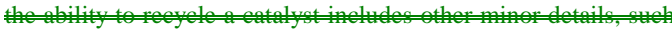
70 f f and its consecutive reuse. This aspect is essentially important

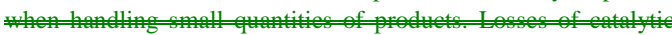
materal are frequent during op a filtering, centrifugation, washing, etc. This has been the case in some 75 tuldes, elaming of

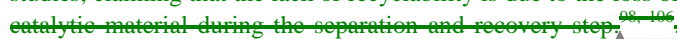
When handling basic solid catalysts, deativation can oceur due the of at $\mathrm{CO}_{2}$, which form Oxidation and/or hydration of the ative phases alo take 80 place by contact with atmospheric air, leading to wrong o th

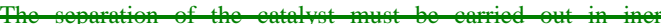
eonditions to avoid this process ${ }^{107}$ When continums conditions W O O O 85 diffieulties on appear, such as most costly equment and of

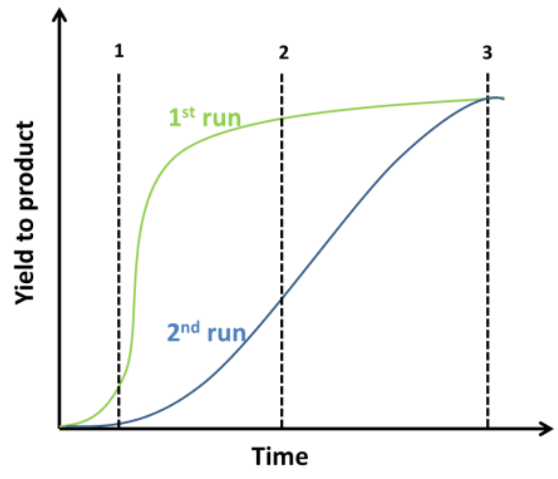

${ }_{90} \mathrm{Fig.} 3$ Hypotheteticalal kinetics showing the deactivation of a catalyst during consecutive catalytic cycles ( $1^{\text {st }}$ and $2^{\text {nd }}$ run)

When batch reactions are carried out, it must be stressed that the ability to recycle a catalyst includes other minor details, such as the effective recovery of the solid from the reaction medium 95 and its consecutive reuse. This aspect is essentially important when handling small quantities of products. Losses of catalytic material are frequent during operations such as-_filtrationtering. centrifugation, washing, etc. This has been the case in some studies, claiming that the lack of recyclability is due to the loss of 100 catalytic material during the separation and recovery step ${ }^{98,-106}$
Field Code Changed

Formatted: Justified

Field Code Changed 
When handling basic solid catalysts, deactivation can occur due to the presence of atmospheric $\mathrm{CO}_{2}=$ which form carbonates. Oxidation and/or hydration of the active phases can also take place by contact with atmospheric air, leading to wrong 5 conclusions on the deactivation and reutilization of the catalysts. The separation of the catalyst must be carried out underin inert conditions to avoid these issuesis process. ${ }^{107}$ When continuous conditions are employed,- handling problems are avoided ${ }_{2,-5}$ although other difficulties can appear-_- - such as costly 10 equipment and necessity of shaping the catalyst.

In some cases, the activity in the successive cycles increases despite in spite of the deactivation effect. This is due to the presence of -induction periods in the reaction. This means, that the catalyst needs time to undergo a structural change (e.g.

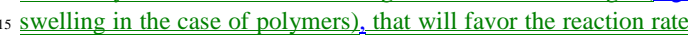
and thus, - increase the conversion in subsequent catalytic cycles. ${ }^{64}$

When evaluating the reusability of a the catalysts. the characterization of the used catalyst is essential to understand the

20 deactivation mechanisms, and to propose an adequate regeneration procedure. The study of the composition, crystalline phases, surface area and other properties will provide useful insights of the possible deactivation phenomena taking place during the reaction.

${ }^{25}=$ The most common regeneration mechanism for fouling and/or poisoning is the thermal calcination treatment, which will remove the deposited species. This type of treatment has been described in numerous scientific studies. ${ }^{108-110}$ Note that the oxidation of adsorbed coke species by thermal treatment may not be possible 30 if the catalyst is not stable at the required temperature or is sensitive to oxidation. In the latter case gasification of the deposits can be-also be achieved with other milder oxidants agents like water $\mathrm{H}_{2} \mathrm{O}$ - or even with inert or reducing agents like $\underline{\underline{\mathrm{N}}}_{2}$ and $\mathrm{H}_{2}$. Obviously, removal of deposits or poisons present on 35 the surface of the catalyst will not recover the initial activity if there is deactivation by leaching. ${ }^{111}$ Other regeneration procedures include rinsing with solvents, acid or basic solutions, drying, or even chemical treatment aiming at removing the deposits and/or poisons to restituting the active sites, such as 40 oxidizing the coke by $\mathrm{H}_{2} \underline{\underline{\mathrm{O}}}_{2}{ }_{2}^{112 ;}, \underline{\underline{113}}$
Field Code Changed

Field Code Changed

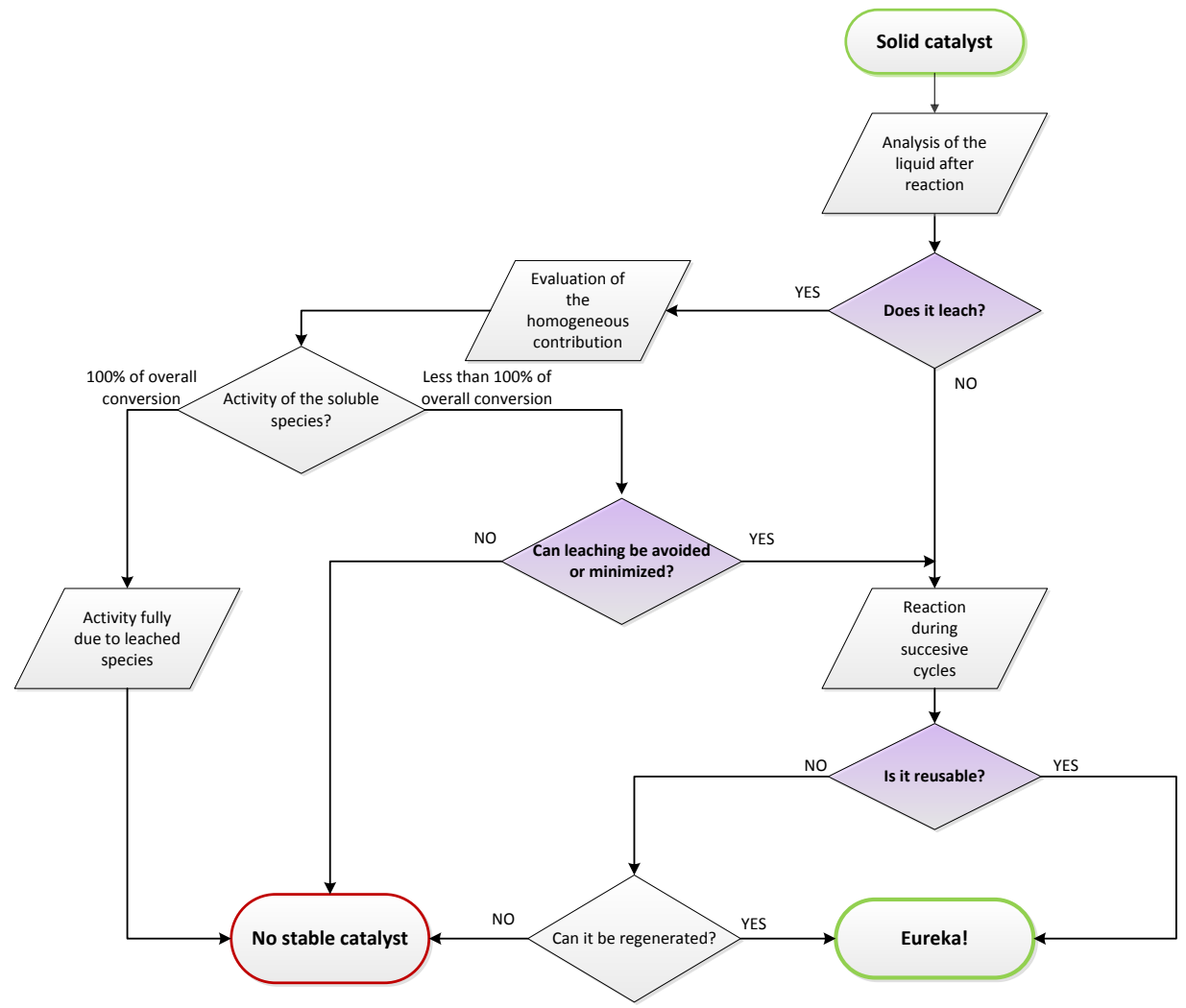

Fig.2 Decision flowchart to evaluate the stability and reusability of solid catalysts in liquid phase.

-In om thes in 45 spite of the deactivation effect. This is due to the presence of

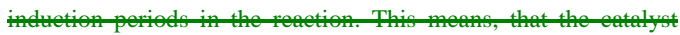

netime the af

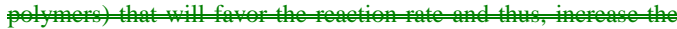
conversion in subsequent catalytic cycles ${ }^{64}$ 50 When evaluating the reusability of the catalysts, the 
ehanerention of the deacivation mechanisms, and to propos an adequate regeneration procedure. The stuly of the composition, crystalline

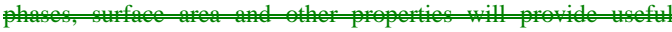
5 insights of the possible deactivation phenomena taking place denting

The poisoning is the thermal calcination treatment, which will remove the deposited species. This tye of trentment has been described in numerous seientific studies ${ }^{10-110}$ Note that the oxidation of adsorbed coke species by thermal treatment may not be possible if the ataly is stable at the requived temperature of In the lat of a the deposits can be also achieved with other milder oxidants agents 15 like $\mathrm{H}_{2} \mathrm{\theta}$ - or even with inert or reducing agents like $\mathrm{N}_{2}=$ and $\mathrm{H}_{2}=$ Obviously, removal of deposits or poisons present on the surface of the catalyst will not recover the initial activity if there is

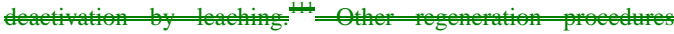
include rinsing with solvents, acid or basic solutions, drving, of 20 even chemical treatment aiming at removing the deposits and/or

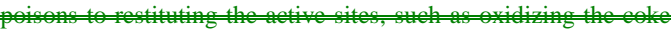
by $\mathrm{H}_{2} \mathrm{\theta}_{2}=\frac{112,113}{=1,13}$

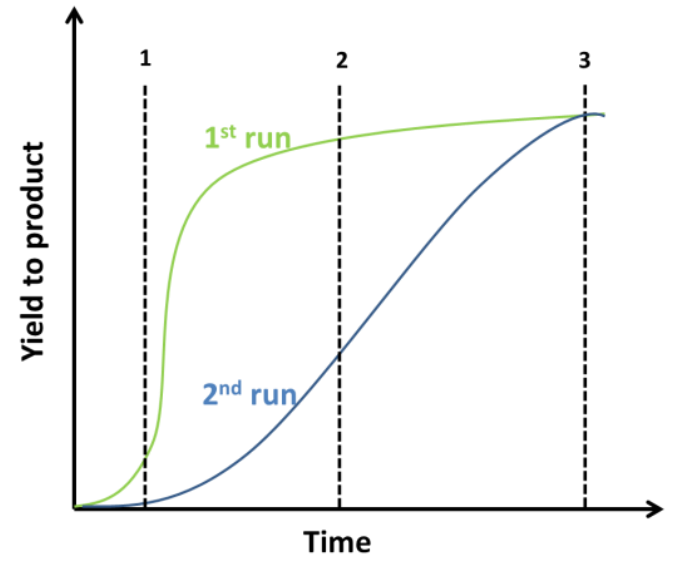

Fig. 3 Hypothetieal kineties showing the deactivation of a eatalyst during consecutive catalytic eycles $\left(1^{\text {st and } 2^{\text {hd }}}{ }^{\text {aun }}\right)$.

\section{General remarks}

The main objective of this tutorial review is to draw the attention 30 and give general guidelines regarding the phenomenon of the leaching of solid catalysts in liquid media, especially to those not familiarized with the utilization of solid catalysts in liquid processes. Leaching is very often underestimated and not properly evaluated. For example, in a recent study by Hájek et al. 35 on production of biodiesel using Kpotassium - based catalyst by Hájek at.it was, the authers-remarked, that not many of the previous studies even addressed the problem of leaching. ${ }^{114}$ Omitting this crucial information in the discussion of the activity of the catalyst can lead to misleading conclusions and should be 40 avoided.

Ideally, the extent of leaching should be negligible, but in most reactions performed of the cases of reans in polar solvents and at high temperatures, ${ }_{-}$some leaching will always be present. However, this does not necessarily -mean that-if a the -given 45 catalyst-leads to leaching, it_cannot be utilized in any industrial process. Every reaction case will require a particular evaluation of the pros and cons of the use of the catalyst, together with a study of possible ways to design the catalytic process. The presence of leaching can have environmental consequences too. ${ }_{50}$ In the case of toxic elements, recovery of the leached species must be conducted to prevent downstream contamination. This implies the capture of the leached species by different methods to transfer them to a solid phase with the consequent concentration. In the case of expensive catalyst, the reconstitution or the 55 extraction of the active catalytic species by different metallurgic procedures can be an interesting option to recycle the leached species in other applications, including as a catalyst. The lifetime of the catalyst needs to be taken into account when studying the feasibility of the industrial process, and the possibility of 60 regeneration. Even though the presence of leaching will shorten the catalyst lifetime, an economical study will determine if the catalytic process is still viable.

-Finally, it has to be noted that in some contexts,- the leaching 65 of expensive metals from used catalysts is a standard procedure in metal recovery processes, which enables the recycling of the metal from waste catalysts and represents a necessary step to minimize environmental impacts.

\section{9. Conclusions}

New questions arise when studying the stability of solid catalysts in liquid media compared to gas phase reactions $;-$ the solubility of the catalyst and the homogeneous contribution of the leached species. An increasing number of scientific articles in the context 75 of green chemistry and biorefineries deals with reactions in liquid phase using solid catalysts, and not all of them account for the possible presence of leaching. It is imperative to remark that the reusability of the catalyst during several catalytic cycles by itself does not imply catalyst stability. If $\underline{\text { a homogeneous catalytic }}$ 80 contribution is present, the total activity can be due to a small fraction of soluble species. This is why leaching tests and measurements of homogeneous catalytic contribution are indispensable to clearly rule out the deactivation by leaching.

This review is aimed as a road map to study the stability of 85 solid catalysts in liquid media. The first step comprises the detection of the presence of leaching and the estimation of its importance. Second, some procedures have been given to try to minimize the extent of leaching. Finally, the reusability of the catalyst and the lifetime need to be addressed.

\section{Acknowledgments}

The authors would like to acknowledge funding and contributions from Centre for Catalysis and Sustainable Chemistry, DTU Chemistry, Institute of Catalysis and Petrochemistry, CSIC and
Field Code Changed

Field Code Changed

Formatted: Left

Formatted: 08 Article Text 
Haldor Topsøe A/S to part of the reported work....

References

1. B. Kamm, P. R. Gruber and M. Kamm, Biorefineries - Industrial Processes and Products Status Quo and Future Directions, WileyVCH, 2005.

2. Y.-C. Lin and G. W. Huber, Energy \& Environmental Science, 2009, 2, 68-80.

3. S. Liu, H. Lu, R. Hu, A. Shupe, L. Lin and B. Liang, Biotechnology Advances, 2012, 30, 785-810.

4. J. J. Bozell, S. K. Black, M. Myers, D. Cahill, W. P. Miller and S. Park, Biomass and Bioenergy, 2011, 35, 4197-4208.

15 5. T. Vancov, A.-S. Alston, T. Brown and S. McIntosh, Renewable Energy, 2012, 45, 1-6.

6. T. Ståhlberg, W. Fu, J. M. Woodley and A. Riisager, Chemsuschem, 2011, 4, 451-458.

7. S. Lima, M. M. Antunes, M. Pillinger and A. A. Valente, ChemCatChem, 2011, 3, 1686-1706.

8. J. N. Chheda, G. W. Huber and J. A. Dumesic, Angewandte Chemie International Edition, 2007, 46, 7164-7183.

9. A. Corma, S. Iborra and A. Velty, Chemical Reviews, 2007, 107, 2411-2502.

25 10. D. M. Alonso, J. Q. Bond and J. A. Dumesic, Green chemistry, 2010, 12, 1493-1513.

11. C.-H. Zhou, X. Xia, C.-X. Lin, D.-S. Tong and J. Beltramini, Chemical Society Reviews, 2011, 40, 5588-5617.

12. C.-Z. Liu, F. Wang, A. R. Stiles and C. Guo, Applied Energy, 2012, 92, 406-414.

13. R. Karinen, K. Vilonen and M. Niemelä, Chemsuschem, 2011, 4, 1002-1016.

14. J. S. Kruger, V. Nikolakis and D. G. Vlachos, Current Opinion in Chemical Engineering, 2012, DOI: 10.1016/j.coche.2012.06.003.

35 15. J. C. Serrano-Ruiz, R. Luque and A. Sepulveda-Escribano, Chemical Society Reviews, 2011, 40, 5266-5281.

16. P. Gallezot, Chemical Society Reviews, 2012, 41, 1538-1558.

17. A. Toledano, L. Serrano and J. Labidi, Journal of Chemical Technology \& Biotechnology, 2012, DOI: 10.1002/jctb.3799, n/an/a.

18. M. P. Pandey and C. S. Kim, Chemical Engineering \& Technology, 2011, 34, 29-41.

19. M. E. Borges and L. Díaz, Renewable and Sustainable Energy Reviews, 2012, 16, 2839-2849.

4520 K. Pathak, K. M. Reddy, N. N. Bakhshi and A. K. Dalai, Applied Catalysis A: General, 2010, 372, 224-238.

21. R. D. Cortright, R. R. Davda and J. A. Dumesic, Nature, 2002, 418, 964-967.

22. F. K. Kazi, A. D. Patel, J. C. Serrano-Ruiz, J. A. Dumesic and R. P.

Anex, Chemical Engineering Journal, 2011, 169, 329-338.

23. Y. Roman-Leshkov, C. J. Barrett, Z. Y. Liu and J. A. Dumesic, Nature, 2007, 447, 982-985.

24. C. Bartholomew, in Kirk-Othmer Encyclopedia of Chemical Technology, John Wiley \& Sons, Inc., 2000, DOI: 10.1002/0471238961.1415021218150209.a01.pub2.

55 25. H. Bartholomew, Applied Catalysis A: General, 2001, 212, 17 60

26. I. W. C. E. Arends and R. A. Sheldon, Applied Catalysis A: General, 2001, 212, 175-187.

60 27. M. Besson and P. Gallezot, Catalysis Today, 2003, 81, 547-559.

28. I. W. C. E. Arends, R. A. Sheldon, M. Wallau and U. Schuchardt, Angewandte Chemie - International Edition in English, 1997, 36, 1144-1163.

29. R. Rinaldi and F. Schüth, Energy and Environmental Science, 2009, 2, 610-626.

30. P. Mäki-Arvela, B. Holmbom, T. Salmi and D. Y. Murzin, Catalysis Reviews - Science and Engineering, 2007, 49, 197-340.
31. M. Guisnet and F. R. Ribeiro, in Deactivation And Regeneration Of Zeolite Catalysts, DOI: doi:10.1142/9781848166387_0001, pp. 3-18.

32. A. C. Alba-Rubio, F. Vila, D. M. Alonso, M. Ojeda, R. Mariscal and M. López Granados, Applied Catalysis B: Environmental, 2010, 95, 279-287.

33. N. Luo, K. Ouyang, F. Cao and T. Xiao, Biomass and Bioenergy, 2010, 34, 489-495.

34. R. M. Ravenelle, J. R. Copeland, W.-G. Kim, J. C. Crittenden and C. Sievers, ACS Catalysis, 2011, 1, 552-561.

35. L. Vilcocq, A. Cabiac, C. Especel, S. Lacombe and D. Duprez, Catalysis Communications, 2011, 15, 18-22.

80 36. R. M. Ravenelle, F. Schüßler, A. D'Amico, N. Danilina, J. A. van Bokhoven, J. A. Lercher, C. W. Jones and C. Sievers, The Journal of Physical Chemistry C, 2010, 114, 19582-19595.

37. E. S. Vasiliadou and A. A. Lemonidou, Applied Catalysis A: General, 2011, 396, 177-185.

85 38. X. Hu, C. Lievens, D. Mourant, Y. Wang, L. Wu, R. Gunawan, Y. Song and C.-Z. Li, Applied Energy, 2013, 111, 94-103.

39. J. M. Fraile, E. García-Bordejé and L. Roldán, Journal of Catalysis, 2012, 289, 73-79.

40. J. A. Melero, L. F. Bautista, G. Morales, J. Iglesias and D. Briones, Energy \& Fuels, 2008, 23, 539-547.

41. I. Sadaba, M. Ojeda, R. Mariscal, J. L. G. Fierro and M. L. Granados, Applied Catalysis B-Environmental, 2011, 101, 638648.

42. A. Iriondo, J. F. Cambra, V. L. Barrio, M. B. Guemez, P. L. Arias, M. C. Sanchez-Sanchez, R. M. Navarro and J. L. G. Fierro, Applied Catalysis B: Environmental, 2011, 106, 83-93.

43. V. R. Gangwal, J. van der Schaaf, B. F. M. Kuster and J. C. Schouten, Journal of Catalysis, 2005, 232, 432-443.

44. R. Tschentscher, T. A. Nijhuis, J. van der Schaaf and J. C. Schouten, Industrial \& Engineering Chemistry Research, 2011, 51, $1620-1634$

45. A. Ciftci, B. Peng, A. Jentys, J. A. Lercher and E. J. M. Hensen, Applied Catalysis A: General, 2012, 431-432, 113-119.

46. R. A. Sheldon, M. Wallau, I. W. C. E. Arends and U. Schuchardt, Accounts of Chemical Research, 1998, 31, 485-493.

47. T. Okuhara, Chemical Reviews, 2002, 102, 3641-3666.

48. A. Zheng, C. Xia, Y. Xiang, M. Xin, B. Zhu, M. Lin, G. Xu and X Shu, Catalysis Communications, 2014, 45, 34-38.

49. B. N. Zope, S. E. Davis and R. J. Davis, Topics in Catalysis, 2012, $55,24-32$.

50. W. Luo, U. Deka, A. M. Beale, E. R. H. van Eck, P. C. A. Bruijnincx and B. M. Weckhuysen, Journal of Catalysis, 2013, 301, 175-186

51. R. Oza and S. Patel, Res. J. Recent Sci., 2012, 1, 434-443.

115 52. M. Lopez Granados, D. Martin Alonso, I. Sadaba, R. Mariscal and P. Ocon, Applied Catalysis B-Environmental, 2009, 89, 265-272.

53. J. Zhang, S. Wu, B. Li and H. Zhang, Catalysis Communications, 2012, 29, 180-184

54. A. S. Dias, M. Pillinger and A. A. Valente, Microporous and Mesoporous Materials, 2006, 94, 214-225.

55. I. Sadaba, S. Lima, A. A. Valente and M. Lopez Granados, Carbohydrate Research, 2011, 346, 2785-2791.

56. J. Ni, D. Rooney and F. C. Meunier, Applied Catalysis B: Environmental, 2010, 97, 269-275.

12557 T. Ståhlberg, E. Eyjólfsdóttir, Y. Y. Gorbanev, I. Sádaba and A. Riisager, Catalysis Letters, 2012, 142, 1089-1097.

58. M. Kouzu, J. S. Hidaka, K. Wakabayashi and M. Tsunomori, Applied Catalysis A: General, 2010, 390, 11-18.

59. J. S. Kruger, V. Nikolakis and D. G. Vlachos, Applied Catalysis A: General, 2014, 469, 116-123.

60. S. Lima, M. M. Antunes, A. Fernandes, M. Pillinger, M. F. Ribeiro and A. A. Valente, Applied Catalysis A: General, 2010, 388, 141148.

61. A. K. Endalew, Y. Kiros and R. Zanzi, Biomass and Bioenergy, $2011,35,3787-3809$

62. K. Suwannakarn, E. Lotero, J. G. Goodwin Jr and C. Lu, Journal of Catalysis, 2008, 255, 279-286.

63. D. E. López, J. G. Goodwin Jr, D. A. Bruce and S. Furuta, Applied Catalysis A: General, 2008, 339, 76-83.
Comment [arii2]: Change full journal names to abbreviations, I guess?
Formatted: Justified 
64. X. Mo, D. E. López, K. Suwannakarn, Y. Liu, E. Lotero, J. G. Goodwin Jr and C. Lu, Journal of Catalysis, 2008, 254, 332-338.

65. B. Hamad, R. O. Lopes de Souza, G. Sapaly, M. G. Carneiro Rocha, P. G. Pries de Oliveira, W. A. Gonzalez, E. Andrade Sales and N. Essayem, Catalysis Communications, 2008, 10, 92-97.

I 66. A. P. Soares Dias, J. Bernardo, P. Felizardo and M. J. Neiva Correia, Energy, 2012, 41, 344-353.

67. M. L. Granados, M. D. Z. Poves, D. M. Alonso, R. Mariscal, F. C. Galisteo, R. Moreno-Tost, J. Santamaría and J. L. G. Fierro,

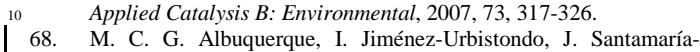
González, J. M. Mérida-Robles, R. Moreno-Tost, E. RodríguezCastellón, A. Jiménez-López, D. C. S. Azevedo, C. L. Cavalcante $\mathrm{Jr}$ and P. Maireles-Torres, Applied Catalysis A: General, 2008, 334, 35-43.

1569. S. Benjapornkulaphong, C. Ngamcharussrivichai and K. Bunyakiat, Chemical Engineering Journal, 2009, 145, 468-474.

70. D. M. Alonso, R. Mariscal, M. L. Granados and P. MairelesTorres, Catalysis Today, 2009, 143, 167-171.

20 71. D. M. Alonso, R. Mariscal, R. Moreno-Tost, M. D. Z. Poves and M. L. Granados, Catalysis Communications, 2007, 8, 2074-2080.

72. H. Liu, L. Su, F. Liu, C. Li and U. U. Solomon, Applied Catalysis B: Environmental, 2011, 106, 550-558.

73. M. J. Ramos, A. Casas, L. Rodríguez, R. Romero and Á. Pérez,

| 74 A. A. S. Dias, J. Bernardo, P. Felizardo and M. J. N. Correia, Fuel Processing Technology, 2012, 102, 146-155.

75. C. S. Castro, C. Ferreti, J. I. Di Cosimo and J. M. Assaf, Fuel, 2012, DOI: 10.1016/j.fuel.2012.06.072.

30 76. H. Liu, L. Su, Y. Shao and L. Zou, Fuel, 2012, 97, 651-657.

77. A. P. S. Chouhan and A. K. Sarma, Renewable and Sustainable Energy Reviews, 2011, 15, 4378-4399.

78. W. Xie, Y. Liu and H. Chun, Catalysis Letters, 2012, 142, 352359.

3579 . S. G. Wettstein, J. Q. Bond, D. M. Alonso, H. N. Pham, A. K. Datye and J. A. Dumesic, Applied Catalysis B: Environmental, 2012, 117-118, 321-329.

80. A. M. Hengne and C. V. Rode, Green Chemistry, 2012, 14, 1064 1072 .

40 81. F. Chambon, F. Rataboul, C. Pinel, A. Cabiac, E. Guillon and N. Essayem, Applied Catalysis B: Environmental, 2011, 105, 171181.

| 82. I. G. Baek, S. J. You and E. D. Park, Bioresource Technology, 2012, 114, 684-690

45 83. Z. Wang, B. Pholjaroen, M. Li, W. Dong, N. Li, A. Wang, X. Wang, Y. Cong and T. Zhang, Journal of Energy Chemistry, 2014, 23, 427-434.

84. L. Faba, E. Díaz and S. Ordóñez, Applied Catalysis B: Environmental, 2012, 113-114, 201-211.

50 85. W. Shen, G. A. Tompsett, K. D. Hammond, R. Xing, F. Dogan, C. P. Grey, W. C. Conner Jr, S. M. Auerbach and G. W. Huber, Applied Catalysis A: General, 2011, 392, 57-68.

| 86. I. Sádaba, M. Ojeda, R. Mariscal, R. Richards and M. López Granados, ChemPhysChem, 2012, 13, 3282-3292.

55 87. A. R. Ardiyanti, S. A. Khromova, R. H. Venderbosch, V. A. Yakovlev and H. J. Heeres, Applied Catalysis B: Environmental, 2012, 117-118, 105-117.

| 88. D. J. M. de Vlieger, B. L. Mojet, L. Lefferts and K. Seshan, Journal of Catalysis, 2012, 292, 239-245.

6089. V. V. Costa, M. J. Jacinto, L. M. Rossi, R. Landers and E. V. Gusevskaya, Journal of Catalysis, 2011, 282, 209-214.

| 90. T. Ståhlberg, E. Eyjólfsdóttir, Y. Y. Gorbanev, I. Sádaba and A. Riisager, Catalysis Letters, 2012, 1-9.

| 91. I. Sádaba, Y. Y. Gorbanev, S. Kegnæs, S. S. R. Putluru, R. W.

65 Berg and A. Riisager, ChemCatChem, 2013, 5, 284-293.

| 92. D. An, A. Ye, W. Deng, Q. Zhang and Y. Wang, Chemistry - A European Journal, 2012, 18, 2938-2947.

| 93. M. Verziu, B. Cojocaru, J. Hu, R. Richards, C. Ciuculescu, P. Filip and V. I. Parvulescu, Green Chemistry, 2008, 10, 373-381.

|70 94. T. van Haasterecht, C. C. I. Ludding, K. P. de Jong and J. H. Bitter, Journal of Catalysis, 2014, 319, 27-35.

| 95. J. Han, J. Duan, P. Chen, H. Lou, X. Zheng and H. Hong, Green Chemistry, 2011, 13, 2561-2568.
96. M. Chia, Y. J. Pagán-Torres, D. Hibbitts, Q. Tan, H. N. Pham, A. K. Datye, M. Neurock, R. J. Davis and J. A. Dumesic, Journal of the American Chemical Society, 2011, 133, 12675-12689.

97. Z. Fang, F. Zhang, H.-Y. Zeng and F. Guo, Bioresource Technology, 2011, 102, 8017-8021.

98. I. Agirrezabal-Telleria, J. Requies, M. B. Güemez and P. L. Arias, Applied Catalysis B: Environmental, 2014, 145, 34-32.

99. S. Van de Vyver, J. Thomas, J. Geboers, S. Keyzer, M. Smet, W. Dehaen, P. A. Jacobs and B. F. Sels, Energy \& Environmental Science, 2011, 4, 3601-3610.

100. I. Sádaba, M. Ojeda, R. Mariscal and M. L. Granados, Applied Catalysis B: Environmental, 2014, 150-151, 421-431.

101. N. Alonso-Fagúndez, V. Laserna, A. C. Alba-Rubio, M. Mengibar, A. Heras, R. Mariscal and M. L. Granados, Catalysis Today, 2014, 234, 285-294.

102. B. J. O'Neill, D. H. K. Jackson, A. J. Crisci, C. A. Farberow, F. Shi, A. C. Alba-Rubio, J. Lu, P. J. Dietrich, X. Gu, C. L. Marshall, P. C. Stair, J. W. Elam, J. T. Miller, F. H. Ribeiro, P. M. Voyles, J. Greeley, M. Mavrikakis, S. L. Scott, T. F. Kuech and J. A. Dumesic, Angewandte Chemie - International Edition, 2013, 52, 13808-13812.

95 103. C. J. Barrett, J. N. Chheda, G. W. Huber and J. A. Dumesic, Applied Catalysis B: Environmental, 2006, 66, 111-118.

104. L. Faba, E. Díaz and S. Ordóñez, Biomass and Bioenergy, 2013, 56, 592-599.

105. N. Alonso-Fagúndez, I. Agirrezabal-Telleria, P. L. Arias, J. L. G. Fierro, R. Mariscal and M. L. Granados, RSC Advances, 2014, 4 , 54960-54972.

106. L. Peng, A. Philippaerts, X. Ke, J. Van Noyen, F. De Clippel, G. Van Tendeloo, P. A. Jacobs and B. F. Sels, Catalysis Today, 2010, 150, 140-146.

105 107. R. E. O'Neill, L. Vanoye, C. De Bellefon and F. Aiouache, Applied Catalysis B: Environmental, 2014, 144, 46-56.

108. M. M. Antunes, S. Lima, A. Fernandes, M. Pillinger, M. F. Ribeiro and A. A. Valente, Applied Catalysis A: General, 2012, 417-418, 243-252.

110109 . A. S. Dias, S. Lima, P. Brandão, M. Pillinger, J. Rocha and A. A Valente, Catalysis Letters, 2006, 108, 179-186.

110. S. Lima, A. Fernandes, M. Antunes, M. Pillinger, F. Ribeiro and A. Valente, Catalysis Letters, 2010, 135, 41-47.

111. D. M. Alonso, J. Q. Bond, J. C. Serrano-Ruiz and J. A. Dumesic, Green Chemistry, 2010, 12, 992-999.

112. I. Agirrezabal-Telleria, Y. Guo, F. Hemmann, P. Arias and E. Kemnitz, Catalysis Science \& Technology, 2014, DOI: 10.1039/C4CY00129J.

113. D. M. Alonso, J. M. R. Gallo, M. A. Mellmer, S. G. Wettstein and J. A. Dumesic, Catalysis Science and Technology, 2013, 3, 927 931.

114. L. Čapek, M. Hájek, P. Kutálek and L. Smoláková, Fuel, 2014, $115,443-451$ 